\section{(2) OPEN ACCESS}

\title{
Progression of aortic root dilatation and aortic valve regurgitation after the arterial switch operation
}

\author{
Roel L F van der Palen 다, ${ }^{1}$ Teun van der Bom, ${ }^{2}$ Annika Dekker, ${ }_{1}^{1}$ Roula Tsonaka, ${ }^{3}$ \\ Nan van Geloven, ${ }^{3}$ Irene M Kuipers, ${ }^{4}$ Thelma C Konings, ${ }^{5}$ Lukas A J Rammeloo, ${ }^{6}$

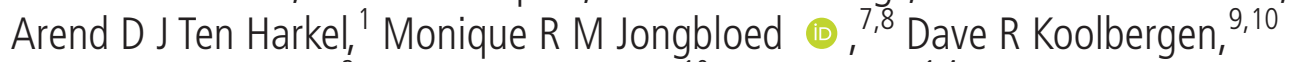 \\ Barbara J M Mulder, ${ }^{2}$ Mark G Hazekamp, ${ }^{10}$ Nico A Blom ${ }^{1,4}$
}

\begin{abstract}
- Additional material is published online only. To view please visit the journal online (http://dx.doi.org/10.1136/ heartjnl-2019-315157).
\end{abstract}

For numbered affiliations see end of article.

\section{Correspondence to}

Dr Roel L F van der Palen, Division of Pediatric Cardiology, Department of Pediatrics, Leiden University Medical Center, 2333 ZA Leiden, The Netherlands; r.vanderpalen@lumc.nl

Received 2 April 2019 Revised 3 May 2019 Accepted 14 May 2019

\section{Check for updates}

(C) Author(s) (or their employer(s)) 2019. Re-use permitted under CC BY-NC. No commercial re-use. See rights and permissions. Published by BMJ.

\footnotetext{
To cite: van der

Palen RLF, van der Bom $T$,

Dekker $A$, et al. Heart

2019;105:1732-1740.
}

\begin{abstract}
Objective To study neo-aortic growth and the evolution of neo-aortic valve regurgitation $(A R)$ in patients with transposition of the great arteries (TGA) after arterial switch operation (ASO) from newborn to adulthood and to identify patients at risk.

Methods Neo-aortic dimensions (annulus/root/ sinotubular junction) and neo-aortic valve regurgitation were assessed serially in 345 patients with TGA who underwent ASO between 1977 and 2015. Linear mixedeffect models were used to assess increase of neo-aortic dimensions over time and to identify risk factors for dilatation. Risk factor analysis for AR by using timedependent Cox regression models.
\end{abstract}

Results After a rapid increase in the first year after ASO and proportional growth in childhood, neo-aortic dimensions continue to increase in adulthood without stabilisation. Annual diameter increase in adulthood was $0.39 \pm 0.06$, $0.63 \pm 0.09$ and $0.54 \pm 0.11 \mathrm{~mm}$ for, respectively, neo-aortic annulus, root and sinotubular junction, all significantly exceeding normal growth. AR continues to develop over time: freedom from $A R \geq$ moderate during the first 25 years post-ASO was $69 \%$. Risk factors for root dilatation were complex TGA anatomy (TGA-ventricular septal defect (VSD), double outlet right ventricle with subpulmonary VSD) and male gender. Risk factors for $A R \geq$ moderate were: complex TGA anatomy and neo-aortic growth. Per millimetre increase in aortic root dimension, there was a $9 \%$ increase in the hazard of $A R \geq$ moderate. Bicuspid pulmonary valve did not relate to the presence of root dilatation or $A R$.

Conclusion After ASO, neo-aortic dilatation proceeds beyond childhood and is associated with an increase in AR incidence over time. Careful follow-up of the neoaortic valve and root function is mandatory, especially in males and in patients with complex TGA anatomy.

\section{INTRODUCTION}

The arterial switch operation (ASO) has been a significant milestone in the evolution of surgery for transposition of the great arteries (TGA) and after its introduction in $1975^{1}$ has gradually replaced the atrial switch procedure worldwide. Despite excellent late survival with good functional ability, residual problems are increasingly recognised during long-term follow-up and include dilatation of the neo-aortic root and neo-aortic valve regurgitation (AR) that may result in neo-aortic root replacement. ${ }^{2-4}$ It has been reported that the neo-aortic root dilates in more than two-thirds of patients after ASO. ${ }^{5}$ However, data on progression of neo-aortic dilatation in adulthood are scarce and controversial. ${ }^{47}$ Similar to root dilatation, concerns have risen about the neo-aortic valve function over time and AR has been described as an important cause for reoperation. ${ }^{8}$ The purpose of this study was to assess neo-aortic growth, neo-aortic valve function and the need for reoperations on neo-aortic valve and/or root during long-term follow-up for the various morphological subtypes of TGA after ASO and, finally, to identify risk factors for root dilatation and AR.

\section{METHODS}

\section{Study population}

All patients who underwent ASO for TGA with intact ventricular septum (TGA-IVS), TGA with ventricular septal defect (TGA-VSD) or double outlet right ventricle with subpulmonary ventricular septal defect (DORV-SP-VSD) at the Center for Congenital Heart Disease Amsterdam-Leiden, The Netherlands, between 1977 and 2015 with two or more echocardiographic follow-up examinations were included in the study. Hospital and outpatient records were reviewed to obtain information on demographics, anthropometrics, morphological and surgical details, aortic reinterventions and mortality.

\section{Echocardiographic measurements}

Retrospective measurements were performed on images derived from transthoracic echocardiograms by two observers. Echocardiographic images were analysed from video cassette tapes (before 2006) and from digital recordings (after 2006) using an offline workstation (EchoPac V.11.1.8., GE Vingmed Ultrasound AS, Norway). Available and good quality images were assessed at the following intervals after ASO: 3, 6, 9 and 12 months, at 2, 3 and 5 years and thereafter with 5 -year intervals up to the last available follow-up recordings. End of follow-up was defined as the date of the last available echocardiogram or the last echocardiogram before root and/or aortic valve reoperation. Neo-aortic diameters were measured from two-dimensional mid-systolic parasternal long-axis views at three levels: (1) neo-aortic valve annulus, from hinge-point to hinge-point; (2) neo-aortic root, at mid-sinus level from internal edge to internal edge; 


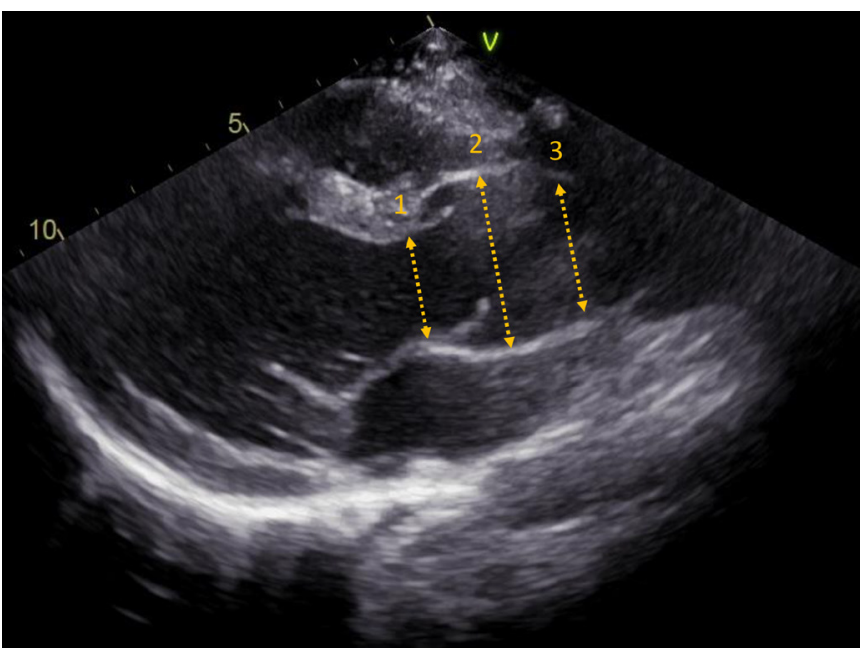

Figure 1 Measurement of neo-aortic dimensions from parasternal long-axis view. Dimensions: (1) neo-aortic valve annulus; (2) neo-aortic root and (3) sinotubular junction.

(3) neo-aortic sinotubular junction (STJ), from internal edge to internal edge (figure 1). To account for the range in body size for neo-aortic measurements during childhood (0-18 years), Z-scores were calculated for each patient by using paediatric reference values and body surface area (BSA) (DuBois method). ${ }^{9}$ Dilatation was defined as Z-score $\geq 2.0$.

Neo-aortic valve regurgitation severity was assessed semiquantitatively by one paediatric cardiologist based on the width of the colour Doppler regurgitation jet at the level of neo-aortic valve on the parasternal long-axis view. ${ }^{10}$ The regurgitation jet width was graded as follows: $0-1 \mathrm{~mm}$ (non-trivial), $1-4 \mathrm{~mm}$ (mild), 5-6 mm (moderate), $>6 \mathrm{~mm}$ (severe). Additionally, left ventricular end-diastolic diameter, as well as the presence of diastolic flow reversal in the proximal descending aorta, was verified to distinguish moderate from severe AR. This method is used in clinical practice and has been described and applied in previous echocardiographic studies on follow-up of AR..$^{11-13}$

\section{Statistical analysis}

Statistical analysis was performed using IBM SPSS Statistics V.23.0 and R V.3.4.0/3.4.2. Clinical characteristics were presented as number (\%) for categorical variables, mean \pm SD for continuous variables or as median (range) where appropriate. To analyse the progression of neo-aortic dimensions at three neo-aortic levels over time, linear mixed-effects models were used. To adequately capture non-linear progression over time and the between-subject variability, natural cubic splines both in the fixed and random-effects term with three knots located at the sample quantiles were used. Potential risk factors known from literature for neo-aortic dilatation were incorporated in the models for the different neo-aortic levels (see details on risk factor inclusion in online supplementary section 1 ). The likelihood ratio test including the Bonferroni correction was used to test for differences in mean neo-aortic profiles over time between TGA subtypes.

Kaplan-Meier analysis was performed to assess the probability of freedom from $\mathrm{AR} \geq$ mild and $\mathrm{AR} \geq$ moderate. The log-rank test was used to test for differences of event-free survival curves among morphological TGA subtypes. To assess the independent predictive value of different covariates (from table 1) on the occurrence of AR, Cox regression models were used. A time-dependent Cox model was used to evaluate the effect of the
Table 1 Demographics and preoperative anatomy

\begin{tabular}{|c|c|}
\hline Data & Study cohort $(n=345)$, no $(\%)$ \\
\hline Male & $229(66.4)$ \\
\hline Age at 1st assessment, median (range) & 1.9 (range $0.04-31.5$ ) years \\
\hline Age at last follow-up, median (range) & 12.2 (range $1.0-39.0$ ) years \\
\hline \multicolumn{2}{|l|}{ Morphological TGA subtype } \\
\hline TGA-IVS & $230(66.7)$ \\
\hline TGA-VSD & $89(25.8)$ \\
\hline DORV-SP-VSD & $26(7.5)$ \\
\hline \multicolumn{2}{|l|}{ Coexisting findings } \\
\hline Arch abnormality & $24(7.0)$ \\
\hline Bicuspid pulmonary valve & $21(6.1)$ \\
\hline Left ventricular ОТО & $12(3.5)$ \\
\hline \multicolumn{2}{|l|}{ Coronary anatomy* } \\
\hline Usual (1LCx-2R, 1L-2CxR) & $275(79.7)$ \\
\hline Other & $60(17.4)$ \\
\hline Intramural course of LAD & $4(1.2)$ \\
\hline Unknown & $6(1.7)$ \\
\hline \multicolumn{2}{|l|}{ Preoperative procedures } \\
\hline Balloon atrial septostomy & $182(52.8)$ \\
\hline Previous PAB & $18(5.2)$ \\
\hline \multicolumn{2}{|l|}{ Arterial switch operation } \\
\hline One-stage & $319(92.5)$ \\
\hline Median age (range) & 8 days ( 0 days -0.6 years) \\
\hline Two stage & $26(7.5)$ \\
\hline Median age (range) & 143 days ( 36 days -5.1 years) \\
\hline \multicolumn{2}{|l|}{ Coronary artery transfer technique } \\
\hline Double button & $197(57.1)$ \\
\hline Single trapdoor, single button & $96(27.9)$ \\
\hline Double trapdoor & $31(9.0)$ \\
\hline Aortic sinus pouch technique & $4(1.2)$ \\
\hline Unknown & $17(4.9)$ \\
\hline Lecompte manoeuvre & $320(92.8)$ \\
\hline
\end{tabular}

changing aortic dimensions over time on risk of AR (see details on inclusion of variables in online supplementary section 1 ). All $\mathrm{p}$ values were two sided with a significance threshold $<0.05$.

\section{RESULTS}

During the study period, 452 patients underwent ASO. Fifty-two patients $(11.5 \%)$ died during follow-up. Mortality in the first postoperative month was $9.3 \%$ (42 patients) and late deaths (>30 days post-ASO) occurred in 10 patients. Early mortality was highest from 1977 to 1987 after start of the ASO programme and early mortality incidence decreased to 3.3\% between 1995 and 2015. Fifty overseas patients were lost to follow-up directly postsurgery and in five patients echocardiographic examinations were either lacking $(n=3)$ or of poor image quality $(n=2)$, leaving 345 patients for the analysis. Baseline patient characteristics are shown in table 1 . The morphological TGA subtypes were: TGA-IVS in $230(66.7 \%)$ patients, TGA-VSD in 89 (25.8\%) patients and DORV-SP-VSD in $26(7.5 \%)$ patients. Baseline characteristics did not significantly differ between the study population and patients lost to follow-up or those who did not survive. Median number of repeated neo-aortic measurements and AR grading was 4 (range 2-9) per patient. 
A
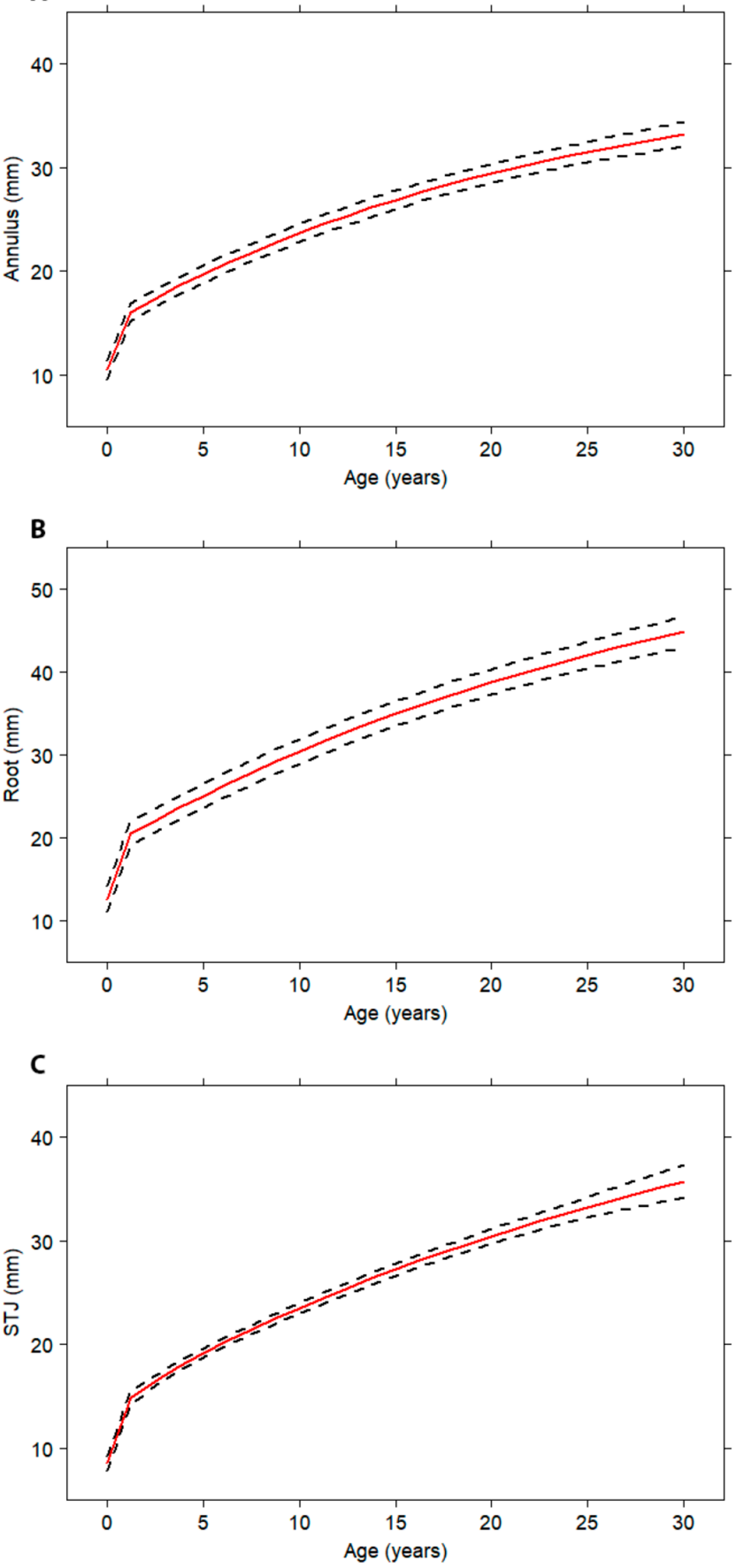
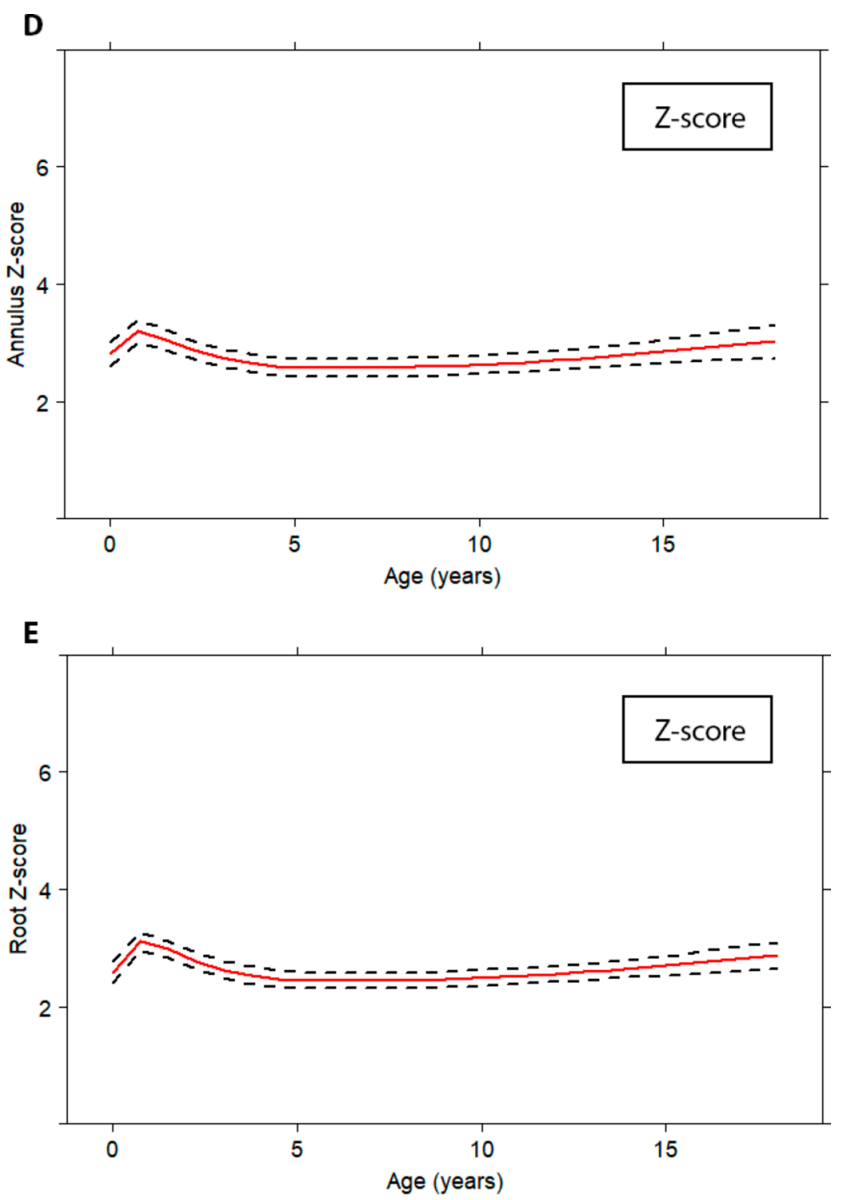

$\mathbf{F}$

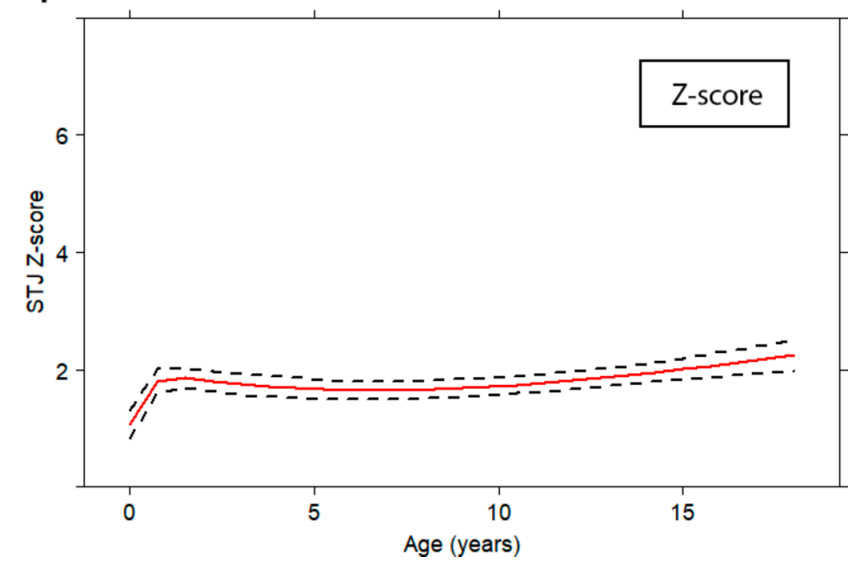

Figure 2 Mean progression of neo-aortic dimensions over time for all patients with TGA. Absolute neo-aortic diameters (A-C); neo-aortic Z-scores (D-F). Mean profiles are plotted with the described risk factors set to the reference level; dashed lines represent $95 \%$ CI. STJ, sinotubular junction; TGA, transposition of the great arteries.

\section{Neo-aortic growth from neonate to adult}

Averaged time-related evolution of the neo-aortic dimensions for all patients with TGA are depicted in figure $2 \mathrm{~A}-\mathrm{C}$. The neo-aortic annulus, neo-aortic root and the STJ all showed similar growth patterns: a rapid increase in the first year after ASO, followed by a nearly linear increase of neo-aortic dimensions in childhood with an ongoing increased growth rate in adulthood. The average diameter progression in adulthood (18-30 years post-ASO) for all patients with TGA was $0.39 \mathrm{~mm} /$ year for the neo-aortic annulus (95\% CI 0.33 to $0.46 \mathrm{~mm} /$ year), $0.63 \mathrm{~mm} /$ year for the neo-aortic root $(95 \% \mathrm{CI} 0.54$ to $0.71 \mathrm{~mm} /$ year) and $0.54 \mathrm{~mm} /$ year for the STJ $(95 \%$ CI 0.43 to $0.65 \mathrm{~mm} /$ year).

For the childhood period, neo-aortic diameters were indexed to body size and depicted as Z-scores (figure 2D-F). A rapid increase in neo-aortic Z-scores was observed for all neo-aortic dimensions in the first year after ASO (average Z-score $>2.5$ for neo-aortic annulus and neo-aortic root and average $Z$-score of 2.0 for STJ), followed by stabilisation at these high Z-score levels during childhood. From 2 to 18 years, no Z-score increase was observed for neo-aortic annulus $(p=0.53)$ and neo-aortic root $(\mathrm{p}=0.79)$. The Z-score for STJ slightly increased within 
TGA subgroups

A

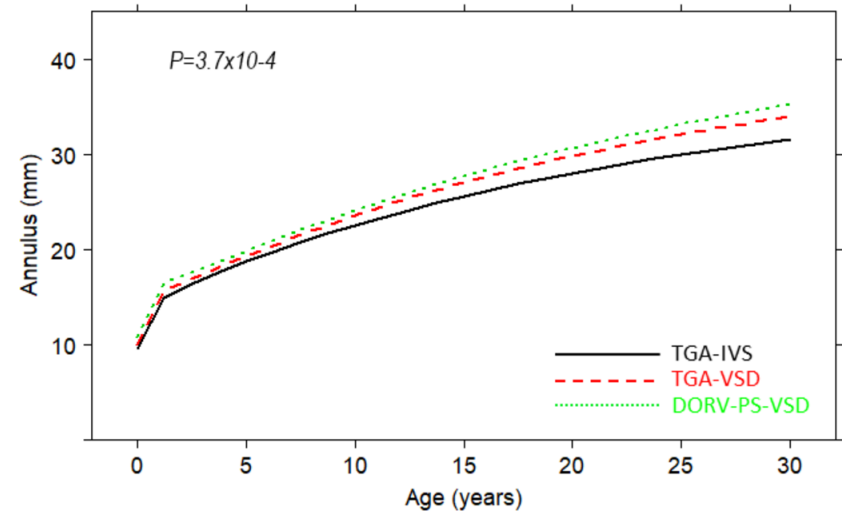

B

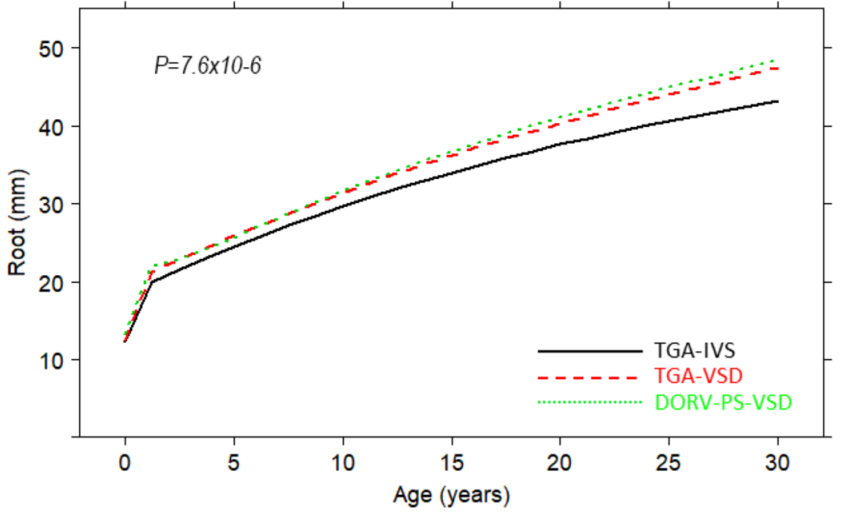

C

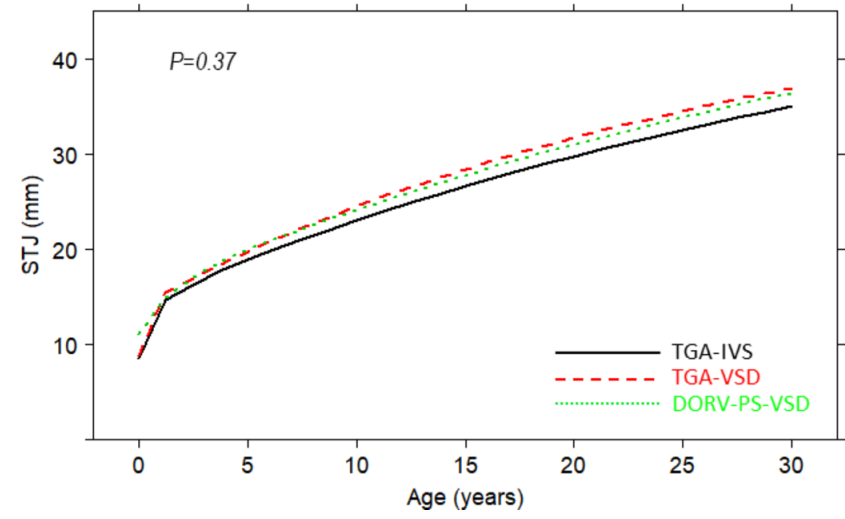

Gender

D

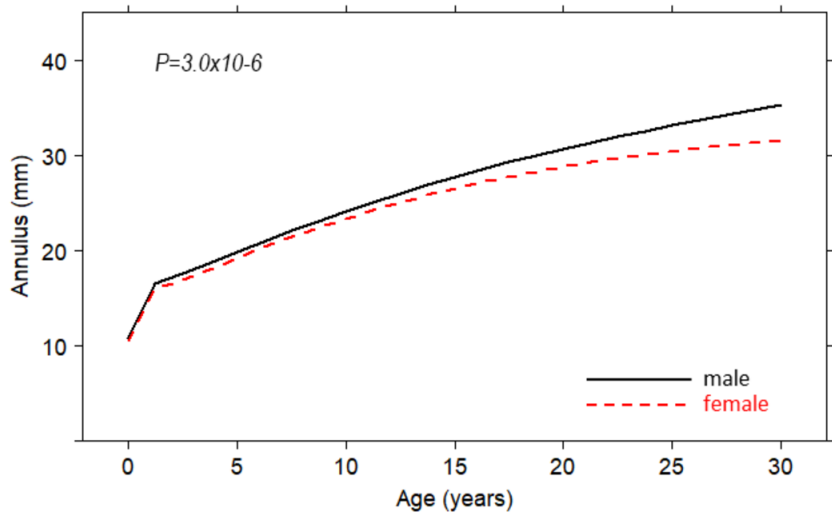

E

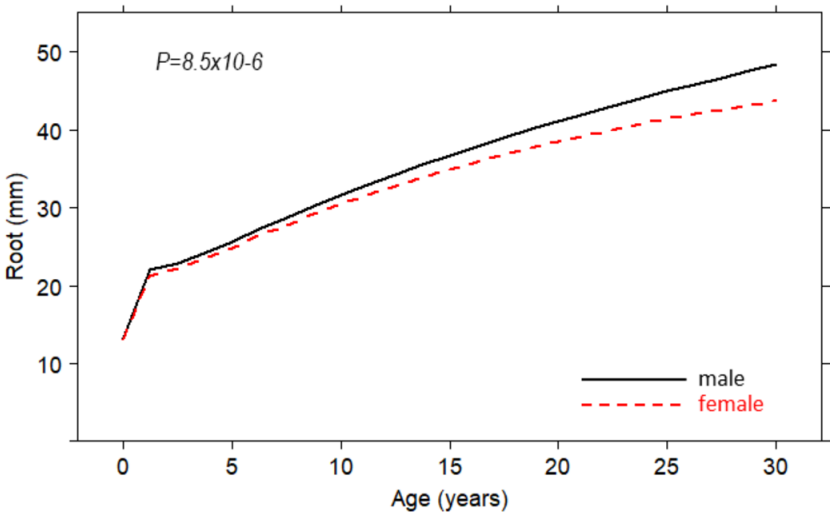

$\mathbf{F}$

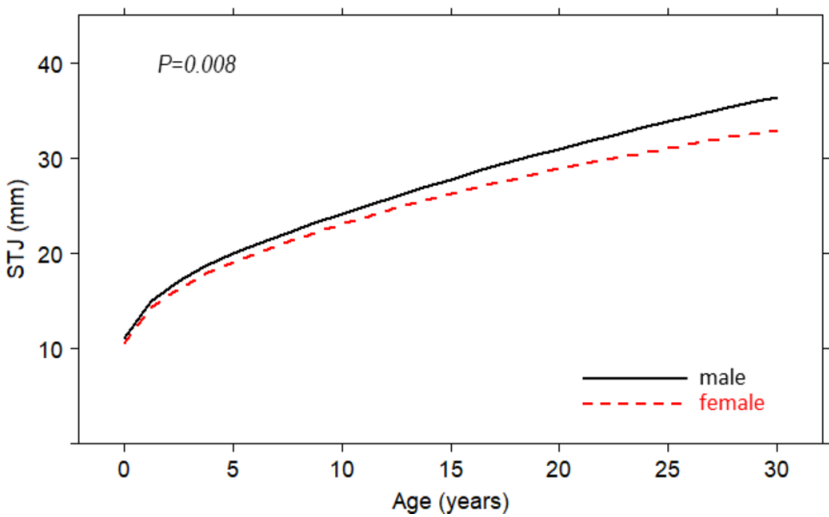

Figure 3 Mean progression of neo-aortic dimensions over time for different TGA subtypes (A-C) and gender (D-F). Mean profiles are plotted with the described risk factors set to the reference level. For Cls (online supplementary figure S1). DORV-SP-VSD, double outlet right ventricle with subpulmonary ventricular septal defect; IVS, intact ventricular septum; STJ, sinotubular junction; TGA, transposition of the great arteries; VSD, ventricular septal defect.

this period $(p=0.005)$, between 15 and 18 years post-ASO (figure 2D-F).

\section{Neo-aortic progression between TGA subtypes}

Figure $3 \mathrm{~A}-\mathrm{C}$ depicts the time-related evolution of the neo-aortic dimensions at three aortic levels for the different TGA subtypes (CI in online supplementary figure $\mathrm{S} 1 \mathrm{~A}-\mathrm{C}$ ). The mean profiles for neo-aortic annulus and neo-aortic root diameters showed significant differences between the three TGA subtypes $\left(p=3.7 \times 10^{-4}\right.$ and $\mathrm{p}=7.6 \times 10^{-6}$, respectively). No difference in mean profiles between TGA subgroups for STJ was found $(p=0.37)$.

Mean increase of the neo-aortic dimensions beyond childhood for the TGA subtypes is depicted in online supplementary table S1. The growth rate slightly decreases after 18 years post-ASO but remained high for the different neo-aortic dimensions in all subtypes. The smallest neo-aortic diameter increase was observed in the TGA-IVS patients and the largest increase in the DORV-SP-VSD patients. 
A

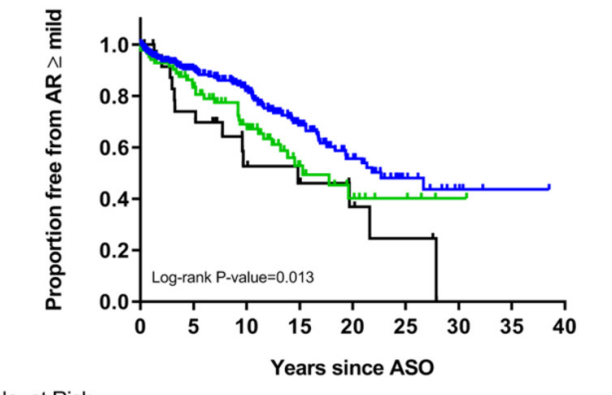

$\begin{array}{lrccccccc}\text { No. at Risk } & & & & & & & & \\ \text { TGA-IVS } & 230 & 169 & 114 & 67 & 34 & 13 & 5 & 1 \\ \text { TGA-VSD } & 89 & 59 & 40 & 16 & 8 & 4 & 1 & 0 \\ \text { DORV-SP-VSD } & 26 & 17 & 9 & 7 & 4 & 2 & 0 & 0\end{array}$

B

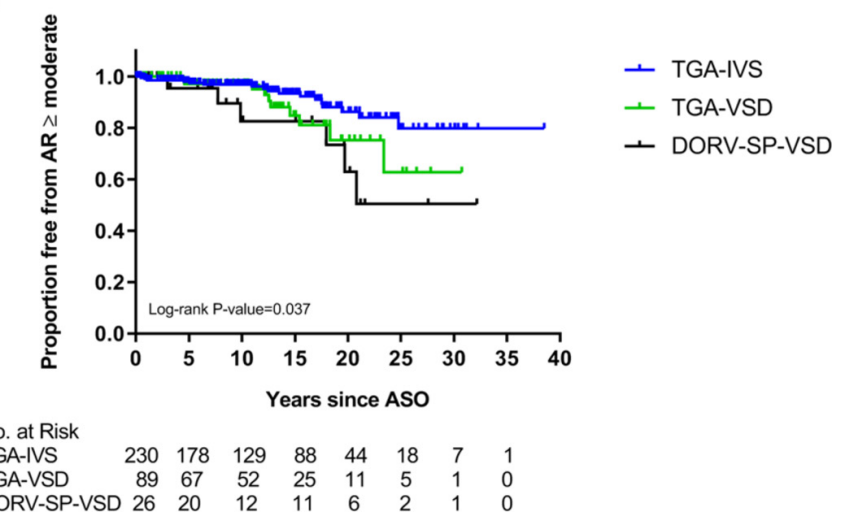

Figure 4 Freedom from at least mild (A) and at least moderate (B) neo-aortic valve regurgitation after ASO. AR, neo-aortic valve regurgitation; ASO, arterial switch operation; DORV-SP-VSD, double outlet right ventricle with subpulmonary ventricular septal defect; IVS, intact ventricular septum; TGA, transposition of the great arteries; VSD, ventricular septal defect.

\section{Risk factors for neo-aortic dilatation}

Morphological TGA subtype and gender were independent risk factors for root dilatation (figure 3A-F). Male patients tend to have larger neo-aortic roots compared with female patients (Annulus $\mathrm{p}=3.0 \times 10^{-6}$; Root $\mathrm{p}=8.5 \times 10^{-6}$; STJ $\mathrm{p}=0.008$ ), of which the effect starts 13 years after ASO (figure $3 \mathrm{D}-\mathrm{F}$; CI in online supplementary figure S1D-F). Explorative risk factor analysis showed that none of the other anatomical and surgical variables from table 1 were associated with progression of neo-aortic root dimensions (online supplementary table S2).

\section{Neo-aortic valve regurgitation}

Neo-aortic valve regurgitation was assessed serially. At last follow-up or just before reoperation for neo-aortic root pathology, thirty-three of the 345 patients with TGA (9.6\%) had at least moderate AR (AR $\geq$ moderate). Moderate or more AR was present in 7.4\% $(n=17)$ of the TGA-IVS, in $11.2 \%(n=10)$ of the TGA-VSD and in 23.1\% $(\mathrm{n}=6)$ of the DORV-SP-VSD patients. Mild or more AR was present in 28.2\% $(n=65)$ of the TGA-IVS, in $36.0 \%(\mathrm{n}=32)$ of the TGA-VSD and in $53.8 \%$ $(n=14)$ of the DORV-SP-VSD patients. The Kaplan-Meier curves for $A R \geq$ mild and $A R \geq$ moderate are shown in figure 4 . The overall probability of freedom from AR $\geq$ moderate was $96 \%$ at 5 years, which decreased to $95 \%, 88 \%, 78 \%$ and $69 \%$ at $10,15,20$ and 25 years after ASO, respectively. The overall freedom from $\mathrm{AR} \geq$ mild was $79 \%$ at 5 years, which decreased to $64 \%, 50 \%, 39 \%$ and $33 \%$ at $10,15,20$ and 25 years after
ASO, respectively. Log-rank test showed significant differences between the TGA subtypes $(p=0.037$ and $p=0.013$ for $\mathrm{AR} \geq$ moderate and $\mathrm{AR} \geq$ mild, respectively).

Results from Cox regression and time-dependent Cox regression analysis for the development of AR are depicted in table 2. TGA morphological subtype was a univariable risk factor for the occurrence of both $\mathrm{AR} \geq$ mild and $\mathrm{AR} \geq$ moderate $(\mathrm{p}=0.009$ and $\mathrm{p}=0.02$, respectively). Furthermore, late ASO (ASO $\geq 6$ months of age) was significantly associated with the occurrence of $\mathrm{AR} \geq$ mild. Aortic diameter increase over time (for neo-aortic annulus and root) were risk factors for development of $\mathrm{AR} \geq$ moderate in the univariable time-dependent Cox analysis. Multivariable models for the diameters showed a 9\% (95\% CI $1 \%$ to $17 \%$ ) increase in the hazard of AR $\geq$ moderate per $\mathrm{mm}$ increase in aortic root diameter dimension (table 2).

\section{Neo-aortic reoperation}

Ten patients $(2.9 \%)$ from the study cohort underwent reoperation on the neo-aortic valve and/or root (table 3). Median age at reoperation was 17.4 (range 7.9-29.0) years. Original diagnoses were TGA-IVS in $3(1.3 \%)$, TGA-VSD in $5(5.6 \%)$ and DORVSP-VSD in two patients (7.7\%). Primary indications for neo-aortic reoperations were root dilatation $(n=4)$ or root dilatation with AR $(n=6)$. Surgical procedures performed were: Bentall operation $(n=6)$, neo-aortic valve replacement $(n=2)$, supracoronary tubular prosthesis for repair of root/STJ $(n=1)$ and switch back operation $(\mathrm{n}=1)$. Additional details on neo-aortic diameters, patient and surgical characteristics are depicted in table 3.

\section{DISCUSSION}

This is the first study that investigated long-term neo-aortic growth and neo-aortic valve function in patients with TGA by analysing serial measurements using a linear mixed-model approach from birth up to 39 years post-ASO. This study demonstrates that neo-aortic root dilatation is progressive and does not stabilise in adulthood and that AR progresses over time. Dilatation did not only involve the neo-aortic root but also the neo-aortic valve annulus and STJ. Morphological TGA subtype (TGA-VSD and DORV-SP-VSD) and male gender were found to be independent risk factors for aortic root dilatation. Furthermore, the progression of root dilatation was a critical factor for impairment of neo-aortic valve function: per millimetre increase in aortic root dimension over time there is an average $9 \%$ increase in the hazard of $\mathrm{AR} \geq$ moderate.

\section{Neo-aortic root dilatation}

Discussion about the neo-aortic growth pattern after ASO in childhood is still ongoing. In the present study, we show that a disproportional increase of neo-aortic sizes occurs in the first year after ASO, followed by a neo-aortic growth rate comparable to normal somatic growth from 2 to 18 years of age although at a higher Z-score level. Similar findings were reported by smaller mid-term follow-up studies. ${ }^{14}{ }^{15}$ In contrast, other studies reported ongoing disproportional neo-aortic root growth during the entire childhood period ${ }^{13}$ or disproportionate growth till the age of 10 years followed by stabilisation until 18 years of age. ${ }^{16}$ This study extends the current knowledge on aortic growth patterns by its unique serial evaluation of neo-aorta dimensions in these patients from birth to adulthood. A major finding of this study and a concern for the future is the ongoing growth of the neo-aortic root beyond childhood, after somatic growth stops. Our findings are in agreement with those of a cardiac MRI study using longitudinal data 
Table 2 Cox model (univariable model) and time-dependent Cox model for the risk on neo-aortic valve regurgitation

\begin{tabular}{|c|c|c|c|c|c|c|}
\hline \multirow[b]{2}{*}{ Risk factors } & \multicolumn{3}{|c|}{$A R \geq$ moderate $(n=33)$} & \multicolumn{3}{|c|}{$A R \geq \operatorname{mild}(n=111)$} \\
\hline & Events/total & HR $(95 \% \mathrm{Cl})$ & $P$ value & Events/total & HR $(95 \% \mathrm{Cl})$ & $P$ value \\
\hline Morphological subtype & & & 0.02 & & & 0.009 \\
\hline TGA-IVS* & $17 / 230$ & $\operatorname{Ref}(1)$ & & $65 / 230$ & $\operatorname{Ref}(1)$ & \\
\hline TGA-VSD & $10 / 89$ & 2.01 (0.92 to 4.38$)$ & 0.08 & $32 / 89$ & 1.71 (1.08 to 2.71$)$ & 0.02 \\
\hline DORV-SP-VSD & $6 / 26$ & 3.55 (1.38 to 9.15$)$ & 0.01 & $14 / 26$ & 2.28 (1.21 to 4.28$)$ & 0.01 \\
\hline \multicolumn{7}{|l|}{ Gender } \\
\hline Malet & $26 / 228$ & $\operatorname{Ref}(1)$ & & $72 / 228$ & $\operatorname{Ref}(1)$ & \\
\hline Female & $7 / 117$ & 0.49 (0.21 to 1.17$)$ & 0.11 & $39 / 117$ & 1.03 (0.67 to 1.58$)$ & 0.89 \\
\hline \multicolumn{7}{|l|}{ Pulmonary valve } \\
\hline Tricuspid‡ & $31 / 324$ & $\operatorname{Ref}(1)$ & & $105 / 324$ & $\operatorname{Ref}(1)$ & \\
\hline Bicuspid & $2 / 21$ & $1.16(0.255 .48)$ & 0.85 & $5 / 21$ & 0.89 (0.34 to 2.30$)$ & 0.49 \\
\hline \multicolumn{7}{|l|}{ Left ventricular ОТО } \\
\hline No§ & $33 / 333$ & $\operatorname{Ref}(1)$ & & $106 / 333$ & $\operatorname{Ref}(1)$ & \\
\hline Yes & $0 / 12$ & $N / A$ & N/A & $5 / 12$ & 1.25 (0.48 to 3.25$)$ & 0.65 \\
\hline \multicolumn{7}{|l|}{ Previous PAB } \\
\hline Noף & $31 / 327$ & $\operatorname{Ref}(1)$ & & $103 / 327$ & $\operatorname{Ref}(1)$ & \\
\hline Yes & $2 / 18$ & 2.02 (0.48 to 8.46$)$ & 0.34 & $8 / 18$ & 1.94 (0.87 to 4.33$)$ & 0.11 \\
\hline \multicolumn{7}{|l|}{ Age $A S O \geq 6$ months } \\
\hline $\mathrm{No}^{* *}$ & $32 / 333$ & $\operatorname{Ref}(1)$ & & $104 / 333$ & $\operatorname{Ref}(1)$ & \\
\hline Yes & $1 / 12$ & 0.83 (0.09 to 7.55$)$ & 0.87 & $7 / 12$ & 2.97 (1.10 to 8.04$)$ & 0.03 \\
\hline \multicolumn{2}{|l|}{ Time-dependent Cox } & \multicolumn{3}{|l|}{$A R \geq$ moderate } & \multicolumn{2}{|l|}{$A R \geq$ mild } \\
\hline Diameter increase & UV/MV & HR $(95 \% \mathrm{Cl})$ & $P$ value & & HR $(95 \% \mathrm{Cl})$ & $P$ value \\
\hline \multirow[t]{2}{*}{ Annulus (per mm) } & UV & 1.14 (1.04 to 1.25$)$ & 0.004 & & $1.04(0.98$ to 1.10$)$ & 0.16 \\
\hline & MV & 1.09 (0.99 to 1.21$) \neq \ddagger$ & 0.09 & & $1.03(0.97$ to 1.09$) \dagger \dagger$ & 0.31 \\
\hline \multirow[t]{2}{*}{ Root (per mm) } & UV & 1.12 (1.05 to 1.21$)$ & 0.001 & & $1.04(1.00$ to 1.10$)$ & 0.07 \\
\hline & MV & 1.09 (1.01 to 1.17$) \ddagger \ddagger$ & 0.04 & & $1.04(0.99$ to 1.09$) \dagger \dagger$ & 0.1 \\
\hline \multirow[t]{2}{*}{ STJ (per mm) } & UV & 1.06 (0.94 to 1.18$)$ & 0.35 & & 0.99 (0.93 to 1.06$)$ & 0.88 \\
\hline & MV & $1.04(0.93$ to 1.15$) \neq \ddagger$ & 0.52 & & $0.99(0.93$ to 1.06$) \dagger \dagger$ & 0.84 \\
\hline
\end{tabular}

Bold refers to the statistically significant $p$ values.

Reference categories of covariate.

*Morphological subtype 'TGA-IVS'.

†Male sex.

‡Tricuspid pulmonary valve.

$\S$ No left ventricular outflow tact obstruction.

IINo previous $\mathrm{PAB}$.

${ }^{* *}$ Age ASO $<6$ months.

††Multivariable analysis adjusted for morphological subtype, gender, pulmonary valve, previous PAB and age ASO $\geq 6$ months of age.

¥¥Multivariable analysis adjusted for morphological subtype and gender.

AR, neo-aortic valve regurgitation; ASO, arterial switch operation; DORV-SP-VSD, double outlet right ventricle with subpulmonary ventricular septal defect; HR, Hazard Ratio;

IVS, intact ventricular septum; MV, multivariable analysis; N/A, not applicable; OTO, outflow tract obstruction; PAB, pulmonary artery banding; STJ, sinotubular junction; TGA,

transposition of the great arteries; UV, univariable analysis; VSD, ventricular septal defect.

from two consecutive MRI examinations in patients between 0 and 29 years post-ASO. ${ }^{17}$

The rate of progression of the aortic root in healthy adult individuals is estimated $0.08 \mathrm{~mm} / \mathrm{year}^{18}$ whereas in patients with TGA the growth rate, depending on its exact morphological subtype, is on average $0.63 \mathrm{~mm} / \mathrm{year}$ as shown by this study. This growth rate is similar to the yearly aortic root growth rate in patients with other diseases associated with aortopathy: for Marfan disease average aortic root growth is reported 0.41 up to $0.49 \pm 0.5 \mathrm{~mm} /$ year before the era of preventive beta-blocker and losartan therapies, ${ }^{1920}$ in bicuspid aortic valve related aortopathy $0.42 \pm 0.6$ up to $0.5 \mathrm{~mm} /$ year for the ascending aorta ${ }^{20}$ and after Ross operation in adulthood $0.43 \mathrm{~mm} /$ year for the neo-aortic root. ${ }^{21}$ The annual growth of the neo-aortic annulus and STJ in adult patients after Ross operation is estimated between 0.33$0.40 \mathrm{~mm}$ and $0.49-0.51 \mathrm{~mm},{ }^{21}{ }^{22}$ respectively. Likewise, after
Ross operation, there is also an initial rapid increase in neo-aortic root dimension followed by a slower ongoing progression.

In this study, we demonstrated complex TGA anatomy (TGAVSD and DORV-SP-VSD) and male gender to be independent risk factors for neo-aortic root dilatation. Complex TGA anatomy is more often reported as risk factor in smaller studies with shorter follow-up duration. ${ }^{5141523}$ Other reported risk factors could not be found in this study, including pulmonary artery banding (PAB) prior to $\mathrm{ASO}^{51623}$ and presence of an aortic arch anomaly. ${ }^{15}$ Remarkably, male gender appeared to be an independent risk factor for larger neo-aortic root growth after ASO. The onset of the differences in aortic diameters between TGA males and females coincides with the age of puberty onset which suggests a possible relation with hormonal changes. Although male gender is known to be related with larger aortic diameters from population studies on aortic sizes in healthy adults, ${ }^{1824}$ this association 
Table 3 Aortic dimensions and patient characteristics for aortic reoperation

Aso Aortic reoperation

\begin{tabular}{|c|c|c|c|c|c|c|c|c|c|c|c|}
\hline \multirow[b]{2}{*}{ Pt } & \multirow[b]{2}{*}{ Diagnosis } & \multirow[b]{2}{*}{ Gender } & \multirow[b]{2}{*}{$\mathrm{PVm}$} & \multirow[b]{2}{*}{ One-stage } & \multirow[b]{2}{*}{ Age (days) } & \multirow[b]{2}{*}{ Lecompte } & \multirow[b]{2}{*}{ Age (years) } & \multirow[b]{2}{*}{ Procedure } & \multirow[b]{2}{*}{ Main indication } & \multicolumn{2}{|c|}{ Aortic dimensions } \\
\hline & & & & & & & & & & $\begin{array}{l}\text { Annulus (mm) } \\
(Z \text {-score)* }\end{array}$ & $\begin{array}{l}\text { Root }(\mathrm{mm}) \\
\text { (Z-score) }\end{array}$ \\
\hline 1. & TGA-IVS & M & T & Y & 2 & Y & 7.9 & AVR+PApl & Root dilatation+AR & $26.0(5.40)$ & $35.8(5.06)$ \\
\hline 3. & TGA-IVS & M & T & Y & 3 & Y & 8.0 & Switchback & Root dilatation+AR & $22.1(4.06)$ & $29.4(3.52)$ \\
\hline 4. & TGA-VSD & M & $\mathrm{T}$ & $\begin{array}{l}\mathrm{N} \\
\text { (Blalock) }\end{array}$ & 403 & Y & 29.0 & $\mathrm{SCT}+\mathrm{MVP}$ & Root dilatation+MR & $25.2(\mathrm{~N} / \mathrm{A})$ & $42.3(\mathrm{~N} / \mathrm{A})$ \\
\hline 7. & TGA-VSD & M & T & Y & 95 & Y & 13.9 & Bentall+Asc & Root dilatation+AR & $28.5(4.87)$ & $49.4(6.63)$ \\
\hline 8. & DORV-SP-VSD & M & T & Y & 210 & Y & 21.8 & Bentall+VSDC & Root dilatation & $27.4(\mathrm{~N} / \mathrm{A})$ & 47.7 (N/A) \\
\hline 9. & DORV-SP-VSD & $M$ & T & $\begin{array}{l}\mathrm{N} \\
\text { (PAB+ } \\
\text { CoAR) }\end{array}$ & 607 & N & 14.0 & Bentall+PVR & Root dilatation+RVOTO & $24.1(3.34)$ & $45.1(5.93)$ \\
\hline 10. & TGA-VSD & $\mathrm{F}$ & T & Y & 115 & Y & 18.9 & Bentall+MVP & Root dilatation+AR + MR & $31.9(\mathrm{~N} / \mathrm{A})$ & $48.0(\mathrm{~N} / \mathrm{A})$ \\
\hline
\end{tabular}

*Z-scores available for patients $<18$ years.

AR, neo-aortic valve regurgitation; Asc, ascending aorta replacement; ASO, arterial switch operation; AVR, aortic valve replacement; Blalock, Blalock shunt; CoAR, repair of aortic coarctationr; DORV-SPVSD, double outlet right ventricle with subpulmonary ventricular septal defect; F, female; IVS, intact ventricular septum; M, male; MVP, mitral valve plasty; N, no; N/A, not applicable; PAB, pulmonary artery banding; PApl, pulmonary artery plasty for supravalvular pulmonary stenosis; Pt, patients; PVm, pulmonary valve morphology; PVR, neo-pulmonary valve replacement; RVOTO, right ventricular outflow tract obstruction; SCT, supracoronary tube; TGA, transposition of the great arteries; T, tricuspid; VSD, ventricular septal defect; VSDc, closure residual ventricular septal defect; $Y$, yes.

has only been reported in one cross-sectional study in patients with complex TGA anatomy after ASO. ${ }^{8}$

The aetiology of ongoing root dilatation most likely has a multifactorial origin. From a postmortem specimen study, it is known that the arterial roots in unoperated TGA patients have a diminished amount and altered distribution of collagen and that the root and neo-aortic valve are less firmly embedded in the myocardium. ${ }^{25}$ Furthermore, the neo-aortic root and pulmonary valve annulus already start larger in patients with TGA immediately after birth (pre-ASO) compared with healthy infants. ${ }^{23}$ This finding is more pronounced in TGA-VSD and DORVSP-VSD patients as compared with TGA-IVS patients. The role of haemodynamic factors in aortic dilatation is unknown. Important geometric alterations in the ascending neo-aorta after ASO with Lecompte manoeuvre may have haemodynamic consequences which potentially impacts on the root diameter. Four-dimensional flow MR imaging in paediatric post-ASO patients has already shown abnormal systolic flow patterns in the ascending aorta in two-thirds of the TGA patients, ${ }^{26}$ but a causal relation still has to be demonstrated.

\section{Neo-aortic valve regurgitation and reoperation}

The occurrence of AR becomes increasingly evident long-term after ASO. Several factors are reported to be associated with AR in literature. These include neo-aortic root dilatation (certain Z-scores: $\geq 2.5$ or $\geq 3.0$ ), ${ }^{11} 1416$ TGA subtype, ${ }^{51114162728}$ older age at ASO, ${ }^{162729}$ previous PAB $^{162728}$ and left ventricular outflow tract obstruction. ${ }^{11} 1629$ In this study, we could only confirm morphological TGA subtype and ASO $>6$ months as risk factors for the development of AR by univariable analysis. More importantly, this study is the first to show an increase in neo-aortic valve annulus and root diameter over time (ie, annulus and root growth) as independent risk factors for moderate or more AR. Every millimetre increase in neo-aortic root size significantly increases the hazard of at least moderate AR. These data suggest that in this group of patients an important underlying mechanism for AR is impaired leaflet coaptation due to progression of the neo-aortic root and valve-annulus dimensions. In addition, the anatomical pulmonary valve itself may be more at risk for valvar incompetence due to differences in histology and anchoring compared with a native aortic valve. ${ }^{25}$ Nevertheless, bicuspid native pulmonary valve morphology was not associated with AR in this study which endorses that a preoperative competent bicuspid valve itself is not a contraindication for ASO when it comes to long-term valve function.

To date, no cases have been reported with aortic rupture or dissection after ASO but in several reoperated patients the anterior wall of the aneurysmatic aorta was observed to be paper-thin and fragile. ${ }^{330}$ Indications for reoperation for aortic root dilatation after ASO to prevent rupture, dissection or progressive AR are unclear. The threshold and timing for aortic root repair are mainly based on absolute diameters rather than indexed aortic diameters (Z-scores) and are adapted from guidelines for aortopathy due to bicuspid aortic valve or connective tissue disease. The current incidence of neo-aortic reoperations in this study and in a recent multicentre study is low. ${ }^{30}$ However, in the present study, already 47 patients (14\%) developed a root diameter $\geq 40 \mathrm{~mm}$, and moderate AR was present in $26 \%$ of them. One-quarter of these patients have not even reached adulthood. The ongoing neo-aortic dilatation, AR progression and its mutual relationship beyond childhood as shown in this study may predict an increased number of root and valve reoperations in the future.

\section{Limitations}

This is a retrospective study and is therefore subject to limitations inherent to the design. A complete series of measurements from birth to adulthood was not available in all patients, with an average of 4 measurements per patient. In general, in the oldest group of patients fewer images at young ages after ASO were available. Therefore, the aortic measurements at young age after ASO $(<5$ years) mainly consisted of data from patients operated in the last two decades. However, as long as those that were followed for a period can be seen as representative for the whole population of similar age, our linear mixed-effect models will provide an unbiased estimate of aortic diameter trends over time. Echocardiographic imaging systems have improved the last decades that might affect accuracy of the measurements. However, only good-quality images were used for analysis. Finally, AR grading remains a semiquantitative estimation and may therefore be subject to observer variability that needs to be taken into account. 
Key messages

\section{What is already known on this subject?}

- Concerns have risen about the neo-aortic root dilatation and neo-aortic valve regurgitation after arterial switch for transposition of the great arteries (TGA) in the long run. Reports on the progression of neo-aortic dilatation and regurgitation into adolescence and adulthood are scarce and controversial and risk factors for neo-aortic dilatation and regurgitation are less clear and contradictory.

\section{What might this study add?}

- The present study shows sustained neo-aortic dilatation without stabilisation in adulthood with an increasing incidence of neo-aortic valve regurgitation over time. It is the first study to show, on the basis of longitudinal data, that progression of root dilatation is the critical factor for impairment of neo-aortic valve function. Complex TGA subtype and male gender are found to be independent risk factors for neo-aortic root dilatation. These data would imply an increasing need for root and/or valve surgery in the (near) future in this patient group.

\section{How might this impact on clinical practice?}

- Life-long follow-up of the neo-aortic dimensions and the neo-aortic valve function after arterial switch operation is indicated, especially in the high-risk patients. Strategies must be devised to prevent neo-aortic dilatation and concomitant neo-aortic valve leakage in the long-term.

\section{CONCLUSIONS}

After ASO, neo-aortic root dilatation is progressive over time and does not stabilise in adulthood with male gender and complex TGA morphology as risk factors. The progressive root dilatation is a critical factor for the impairment of AR long-term after ASO. Based on these data, concerns exist for the neo-aortic root function and the expected increasing need for neo-aortic root and/ or neo-aortic valve reoperations in this ageing group of patients of which the firsts have now reached the age of 40 yearsSupplementary file 2 .

\author{
Author affiliations \\ 'Division of Pediatric Cardiology, Department of Pediatrics, Leiden University Medical \\ Center, Leiden, The Netherlands \\ 2Department of Cardiology, Amsterdam UMC, Univ of Amsterdam, Amsterdam, The \\ Netherlands \\ ${ }^{3}$ Department of Biomedical Data Sciences, Section Medical Statistics, Leiden \\ University Medical Center, Leiden, The Netherlands \\ ${ }^{4}$ Division of Pediatric Cardiology, Department of Pediatrics, Amsterdam UMC, Univ of \\ Amsterdam, Amsterdam, The Netherlands \\ ${ }^{5}$ Department of Cardiology, Amsterdam UMC, Vrije Universiteit Amsterdam, \\ Amsterdam, The Netherlands \\ ${ }^{6}$ Division of Pediatric Cardiology, Department of Pediatrics, Amsterdam UMC, Vrije \\ Universiteit Amsterdam, Amsterdam, The Netherlands \\ ${ }^{7}$ Department of Anatomy\&Embryology, Leiden University Medical Center, Leiden, The \\ Netherlands \\ ${ }^{8}$ Department of Cardiology, Leiden University Medical Center, Leiden, The \\ Netherlands \\ ${ }^{9}$ Department of Cardiothoracic Surgery, Amsterdam UMC, Univ of Amsterdam, \\ Amsterdam, The Netherlands \\ ${ }^{10}$ Department of Cardiothoracic Surgery, Leiden University Medical Center, Leiden, \\ The Netherlands
}

Correction notice Since this article was first published online, footnote and legend edits have been made to table 3.
Acknowledgements We thank Dan Dyar for his collaboration in providing Z-score equations.

Contributors Concept and design of the study: RLFvdP, BJMM, MH and NAB. Acquisition and analysis of the data: RLFvdP, $A D$ and NAB. Interpretation of data: all authors. Drafting of the manuscript: RLFvdP, AD and NAB. Critical revision of the manuscript: all authors. Statistical analysis: RLFvdP, RT and NvG. All authors approved the final version of the manuscript.

Funding The Dutch Heart Foundation supported this research (grant number 2014T087 to van der Palen).

\section{Competing interests None declared.}

\section{Patient consent for publication Not required.}

Ethics approval The local Committee for Medical Ethics of the academic centers approved the study and waived the need for informed consent.

Provenance and peer review Not commissioned; externally peer reviewed.

Open access This is an open access article distributed in accordance with the Creative Commons Attribution Non Commercial (CC BY-NC 4.0) license, which permits others to distribute, remix, adapt, build upon this work non-commercially, and license their derivative works on different terms, provided the original work is properly cited, appropriate credit is given, any changes made indicated, and the use is non-commercial. See: http://creativecommons.org/licenses/by-nc/4.0/.

\section{ORCID iDs}

Roel L F van der Palen http://orcid.org/0000-0003-3640-603X

Monique R M Jongbloed http://orcid.org/0000-0002-9132-0418

\section{REFERENCES}

1 Jatene $A D$, Fontes VF, Paulista PP, et al. Successful anatomic correction of transposition of the great vessels. A preliminary report. Arq Bras Cardiol 1975;28:461-4.

2 Lalezari S, Bruggemans EF, Blom NA, et al. Thirty-year experience with the arterial switch operation. Ann Thorac Surg 2011;92:973-9.

3 Koolbergen DR, Manshanden JS, Yazdanbakhsh AP, et al. Reoperation for neoaortic root pathology after the arterial switch operation. Eur J Cardiothorac Surg 2014;46:474-9.

4 Kempny A, Wustmann K, Borgia F, et al. Outcome in adult patients after arterial switch operation for transposition of the great arteries. Int J Cardiol 2013;167:2588-93.

5 McMahon CJ, Ravekes WJ, Smith EO, et al. Risk factors for neo-aortic root enlargement and aortic regurgitation following arterial switch operation. Pediatr Cardiol 2004;25:329-35.

6 Vandekerckhove KD, Blom NA, Lalezari S, et al. Long-term follow-up of arterial switch operation with an emphasis on function and dimensions of left ventricle and aorta. Eur J Cardiothorac Surg 2009;35:582-8.

7 van der Bom T, van der Palen RL, Bouma BJ, et al. Persistent neo-aortic growth during adulthood in patients after an arterial switch operation. Heart 2014;100:1360-5.

8 Baruteau AE, Vergnat M, Kalfa D, et al. Long-term outcomes of the arterial switch operation for transposition of the great arteries and ventricular septal defect and/or aortic arch obstruction. Interact Cardiovasc Thorac Surg 2016;23:240-6.

9 Pettersen MD, Du W, Skeens ME, et al. Regression equations for calculation of z scores of cardiac structures in a large cohort of healthy infants, children, and adolescents: an echocardiographic study. J Am Soc Echocardiogr 2008:21:922-34.

10 Jenkins KJ, Hanley FL, Colan SD, et al. Function of the anatomic pulmonary valve in the systemic circulation. Circulation 1991;84:11173-9.

11 Co-Vu JG, Ginde S, Bartz PJ, et al. Long-term outcomes of the neoaorta after arterial switch operation for transposition of the great arteries. Ann Thorac Surg 2013;95:1654-9.

12 Cohen MS, Marino BS, McElhinney DB, et al. Neo-aortic root dilation and valve regurgitation up to 21 years after staged reconstruction for hypoplastic left heart syndrome. J Am Coll Cardiol 2003;42:533-40.

13 Marino BS, Wernovsky G, McElhinney DB, et al. Neo-aortic valvar function after the arterial switch. Cardiol Young 2006;16:481-9.

14 Bové T, De Meulder F, Vandenplas G, et al. Midterm assessment of the reconstructed arteries after the arterial switch operation. Ann Thorac Surg 2008;85:823-30.

15 Hutter PA, Thomeer BJ, Jansen P, et al. Fate of the aortic root after arterial switch operation. Eur J Cardiothorac Surg 2001;20:82-8.

16 Schwartz ML, Gauvreau K, del Nido P, et al. Long-term predictors of aortic root dilation and aortic regurgitation after arterial switch operation. Circulation 2004;110(11 Suppl 1):II-128-0.

17 Shepard CW, Germanakis I, White MT, et al. Cardiovascular Magnetic Resonance Findings Late After the Arterial Switch Operation. Circ Cardiovasc Imaging 2016;9.

18 Vasan RS, Larson MG, Levy D. Determinants of echocardiographic aortic root size. The Framingham Heart Study. Circulation 1995;91:734-40.

19 Meijboom LJ, Timmermans J, Zwinderman AH, et al. Aortic root growth in men and women with the Marfan's syndrome. Am J Cardiol 2005;96:1441-4.

20 Detaint $\mathrm{D}$, Michelena HI, Nkomo VT, et al. Aortic dilatation patterns and rates in adults with bicuspid aortic valves: a comparative study with Marfan syndrome and degenerative aortopathy. Heart 2014;100:126-34. 
21 Hanke T, Stierle U, Boehm JO, et al. Autograft regurgitation and aortic root dimensions after the Ross procedure: the German Ross Registry experience. Circulation 2007;116(11 Suppl):I-251-0.

22 Takkenberg JJ, van Herwerden LA, Galema TW, et al. Serial echocardiographic assessment of neo-aortic regurgitation and root dimensions after the modified Ross procedure. J Heart Valve Dis 2006;15:100-6.

23 Hourihan M, Colan SD, Wernovsky G, et al. Growth of the aortic anastomosis, annulus, and root after the arterial switch procedure performed in infancy. Circulation 1993;88:615-20.

24 Wolak A, Gransar H, Thomson LE, et al. Aortic size assessment by noncontrast cardiac computed tomography: normal limits by age, gender, and body surface area. JACC Cardiovasc Imaging 2008;1:200-9.

25 Lalezari S, Mahtab EA, Bartelings MM, et al. The outflow tract in transposition of the great arteries: an anatomic and morphologic study. Ann Thorac Surg 2009;88:1300-5.
26 Geiger J, Hirtler D, Bürk J, et al. Postoperative pulmonary and aortic 3D haemodynamics in patients after repair of transposition of the great arteries. Eur Radiol 2014;24:200-8.

27 Losay J, Touchot A, Capderou A, et al. Aortic valve regurgitation after arterial switch operation for transposition of the great arteries: incidence, risk factors, and outcome. $J$ Am Coll Cardiol 2006;47:2057-62.

28 Delmo Walter EM, Huebler M, Alexi-Meshkishvili V, et al. Fate of the aortic valve following the arterial switch operation. J Card Surg 2010;25:730-6.

29 Lange R, Cleuziou J, Hörer J, et al. Risk factors for aortic insufficiency and aortic valve replacement after the arterial switch operation. Eur J Cardiothorac Surg 2008;34:711-7.

30 Vida VL, Zanotto L, Zanotto L, et al. Left-Sided Reoperations After Arterial Switch Operation: A European Multicenter Study. Ann Thorac Surg 2017>:104:899-906. 